\title{
Peptide Nanoparticle Delivery of Charge-Neutral Splice-Switching Morpholino Oligonucleotides
}

\author{
Peter Järver, ${ }^{1,2, *, \dagger}$ Eman M. Zaghloul,,$^{3,4,{ }^{*}}$ Andrey A. Arzumanov, ${ }^{1}$ Amer F. Saleh, ${ }^{1}$ Graham McClorey, ${ }^{5}$ \\ Suzan M. Hammond, ${ }^{5}$ Mattias Hällbrink, ${ }^{3}$ Ülo Langel, ${ }^{6}$ C.I. Edvard Smith, ${ }^{3}$ \\ Matthew J.A. Wood, ${ }^{5}$ Michael J. Gait, ${ }^{1}$ and Samir EL Andaloussi ${ }^{3,5}$
}

Oligonucleotide analogs have provided novel therapeutics targeting various disorders. However, their poor cellular uptake remains a major obstacle for their clinical development. Negatively charged oligonucleotides, such as 2'-O-Methyl RNA and locked nucleic acids have in recent years been delivered successfully into cells through complex formation with cationic polymers, peptides, liposomes, or similar nanoparticle delivery systems. However, due to the lack of electrostatic interactions, this promising delivery method has been unsuccessful to date using charge-neutral oligonucleotide analogs. We show here that lipid-functionalized cellpenetrating peptides can be efficiently exploited for cellular transfection of the charge-neutral oligonucleotide analog phosphorodiamidate morpholino. The lipopeptides form complexes with splice-switching phosphorodiamidate morpholino oligonucleotide and can be delivered into clinically relevant cell lines that are otherwise difficult to transfect while retaining biological activity. To our knowledge, this is the first study to show delivery through complex formation of biologically active charge-neutral oligonucleotides by cationic peptides.

\section{Introduction}

\section{Oligonucleotide analogs}

C ELlUlar ENTRY AND BIOAVAILABILITY is low for most therapeutic oligonucleotides $(\mathrm{ON})$ and their ability to reach a desired organ or tissue is often very limited. Great efforts have therefore been made in order to develop new delivery systems that can improve tissue penetration and cell entry and enhance bioavailability to a desired intracellular target [1].

Short ONs are widely used to interact with biological nucleic acid targets and therefore utilized as drugs to treat various diseases. There are numerous types of ON analogs of different chemistries, which can be used to interfere with a range of intracellular targets. Commonly used $\mathrm{ON}$ analogs include 2'-O-methyl nucleotide (2'-OMe), locked nucleic acid (LNA), peptide nucleic acid (PNA), and phosphorodiamidate morpholino (PMO). In order to carry out their functions, the ability to cross biological membranes is es- sential to all therapeutic ONs that have intracellular targets. However, all ONs suffer from inefficient delivery into cells and tissues. Studies show that some ON analogs are able to enter certain cell types, such as liver or kidney cells, reasonably efficiently without the aid of any transfection agent [2], but entrapment within endosomal structures still reduce the bioavailability and impede their activity.

\section{Common delivery systems for ON therapeutics}

The most common methods to increase cellular uptake of therapeutic ONs are based on cationic polymers, liposomes, or similar nanoparticle delivery systems [3]. One such system involves cationic peptide delivery vehicles, often referred to as cell-penetrating peptides (CPPs) or peptide transduction domains [4]. They were first introduced in 1994 [5], and since then there has been a constant stream of new delivery peptides with increased delivery efficiency and better pharmacological properties in several applications.

\footnotetext{
${ }^{1}$ Medical Research Council, Laboratory of Molecular Biology, Cambridge Biomedical Campus, Cambridge, United Kingdom.

${ }^{2}$ Center of Infectious Medicine and ${ }^{3}$ Department of Laboratory Medicine, Karolinska Institute, Karolinska University Hospital, Huddinge, Sweden.

${ }^{4}$ Department of Pharmaceutics, Faculty of Pharmacy, Alexandria University, Alexandria, Egypt.

${ }^{5}$ Department of Physiology, Anatomy and Genetics, University of Oxford, Oxford, United Kingdom.

${ }^{6}$ Department of Neurochemistry, Stockholm University, Stockholm, Sweden.

*These authors contributed equally to this work.

${ }^{\dagger}$ Current affiliation: Department of Molecular Biosciences, The Wenner-Gren Institute, Stockholm University, Stockholm, Sweden.
}

(c) Peter Jäver et al. 2015; Published by Mary Ann Liebert, Inc. This Open Access article is distributed under the terms of the Creative Commons License (http://creativecommons.org/licenses/by/4.0), which permits unrestricted use, distribution, and reproduction in any medium, provided the original work is properly credited. 
Cationic ON delivery systems have relied on electrostatic interactions between the negatively charged ON (such as $2^{\prime}$ OMe and LNA) and the positively charged polymer. The cationic delivery vehicle interacts with the anionic $\mathrm{ON}$ and creates a complex, which is taken up into the cells mainly via endocytosis [6]. However, ON analogs such as PNA and PMO have a hydrophobic nature and are charge-neutral. These ON types have not been thought to be compatible with commonly used cationic nanoparticle delivery systems. PNA is based upon repeated $\mathrm{N}$-(2-aminoethyl)-glycine units linked by peptide bonds. Therefore, they can be modified easily, either by total solid phase synthesis or by covalent conjugation in solution to cationic peptide [7,8] or lipid [9] delivery vehicles that dramatically enhance their bioavailability.

The PMO backbone, on the other hand, is based upon morpholine rings instead of deoxyribose and is linked through phosphorodiamidate groups instead of phosphates. PMO ONs are very promising for therapeutic purposes such as steric block of mRNA in both prokaryotes and eukaryotes [10,11] and are currently being tested for pre-mRNA splice-switching in clinical trials for the treatment of Duchenne muscular dystrophy (DMD) in humans, but high doses are needed for effectiveness in treatments [12]. Covalent conjugation of cationic peptides has substantially enhanced the utility of PMO $[13,14]$. However, the lack of a convenient noncovalent delivery system for unmodified PMO ONs has hampered the development of PMO-based ON therapeutics. As discussed previously, the charge-neutral and hydrophobic nature of PMO makes it incompatible with commonly used cationic delivery systems. Thus, it would be of great importance to find a delivery system capable of delivering PMOs into cells that allows for activity screenings of new PMO sequences.

\section{ONs as splice-correcting therapeutics}

In recent years, increased attention has been given to splice-switching ONs (SSOs) to manipulate alternative splicing for therapeutic purposes [15]. Targeting pre-mRNA with SSOs has proven to be a highly promising therapeutic strategy to treat various genetic disorders, such as X-linked agammaglobulinemia (XLA) [16], spinal muscular atrophy (SMA) [17] and previously mentioned DMD [18].

X-linked agammaglobulinemia. XLA is an inherited disease manifested by lack of mature B and plasma cells, with a concomitant pronounced reduction of immunoglobulin levels, making affected individuals highly prone to infections. XLA is caused by defects in the gene encoding Bruton's tyrosine kinase $(B T K)$ [19-21]. Splicing defects have been identified as a frequent cause of this disorder [16]. A PMO ON targeting one of the splice mutations causing XLA and recently demonstrated to successfully restore $B T K$ production [16] is tested in this study.

Spinal muscular atrophy. SMA is caused by reduced levels of the survival motor neuron protein (SMN) [22]. Humans have two nearly identical copies of the $S M N$ gene, SMN1 and SMN2. SMA-affected individuals lack a functional SMN1 gene via mutations or deletions which renders it unable to correctly code for the SMN protein [22,23]. Due to single base pair transition within exon 7, SMN2 mainly generates a shorter transcript lacking exon 7 , which leads to production of an unstable and less functional truncated SMN protein [24-26]. Only 10\%-20\% of SMN2 transcripts retain exon 7 and are able to generate fully functional SMN protein. However, this is not enough to compensate for the loss of SMN1 and results in SMA. Since SMN2 is always present in SMA patients, correction of exon 7 splicing by a SSO in the SMN2 gene is currently the most promising treatment for SMA [27].

Duchenne muscular dystrophy. DMD is caused by mutations in the DMD gene that disrupt the open reading frame and thereby aborting the full translation of its protein product, dystrophin [28], reviewed in [29]. Dystrophin is located underneath the sarcolemma and connects the cytoskeleton to the extracellular matrix. By removing the exon containing the mutation through alternative splicing induced by a SSO, the cell can produce a shorter, yet partially functional protein, and thereby reduce the symptoms of the disease. Alternatively, multiple exons might be removed in order to restore expression of a functional protein [30]. As discussed earlier, SSOs for treatment of DMD have reached clinical trials and hold great promise. These three examples highlight the importance of the development of a safe and efficient screening method for delivery of PMO ON.

Lipopeptides and ON delivery. It has been shown previously that by attaching a lipid moiety to a cationic CPP, the cellular delivery of negatively charged $\mathrm{ON}$ such as $2^{\prime}-\mathrm{OMe}$ oligos, small interfering RNA, and plasmid DNA can be dramatically improved [31-36]. This enhanced activity is probably a result of increased complexation capacity in combination with increased endosomal escape $[35,37,38]$. This class of peptides has been reviewed in [39].

We now sought to test whether the addition of a hydrophobic moiety, such as a lipid, might also help the lipid-CPP hybrid to interact and form complexes with other more hydrophobic structures such as PMO ONs. We initially selected two peptides previously used for highly efficient cellular delivery of anionic nucleic acids, namely PepFect 14 (PF14) [40] and PepFect 6 (PF6) [37]. We assessed their ability to facilitate delivery of splice-switching PMO ONs first in a cell line carrying a luciferase reporter system representing a model for XLA (as described in the methods section) [16]. Further, the peptides were tested for delivery of PMOs into primary SMA patient fibroblasts, and we observed a significant increase in exon inclusion even at very low concentrations. We then extended the study to see if delivery efficacy could be improved by use of other, novel lipopeptides with different peptide designs (Supplementary Table S1; Supplementary Data are available online at www.liebertpub.com/ nat). Lipopeptides representing subcategories were evaluated in the clinically relevant, mdx cell-based DMD model system by measuring the levels of exon skipping of the dystrophin transcript. The most effective lipopeptides were assessed in detail for their abilities to deliver a 25-mer PMO in both SMA and DMD model cell systems. Complex formation was evaluated by nanoparticle tracking analysis (NTA). The effect of different peptide: PMO ratios, doses and the effect of different lipid moieties were also studied. Finally, the toxicity profiles of the different lipopeptides were investigated to determine the applicability of the lipopeptide-mediated delivery of splice-switching PMOs. 


\section{Materials and Methods}

\section{Design of lipopeptides}

Peptides were designed to possess certain properties previously reported to be important for other CPPs that have been successfully exploited for delivery of ONs. Selected peptides and PMO ON sequences (XLA ON; SMA ONs known as ISS-N1; and the DMD ON, known as M23D) are all shown in Table 1 [16,41-43]. PF6 and PF14 are based on the commonly used CPP transportan 10 (TP10) and have previously been used for delivery of various negatively charged ONs [37,40]. RXR peptides (where $\mathrm{X}$ is aminohexanoyl) have commonly been covalently conjugated to PMOs and have proven efficient for delivery both in cultured cells and in vivo [11]. The stearoyl (STR) peptides evolved from the RXR peptides and the design relies on the observation that the cell-penetrating nature of CPPs is driven by a net positive charge. STR peptides have histidine residues incorporated into the sequence, which are mainly uncharged at physiological $\mathrm{pH}$. However, the histidines are protonated at lower $\mathrm{pH}$ (e.g., in maturing endosomes), and hence increase the net positive charge of the CPP [44].

Table 1. Sequences of the Selected Lipopeptides and Phosphorodiamidate Morpholino OligonuCleotides InCluded IN THE STUdy

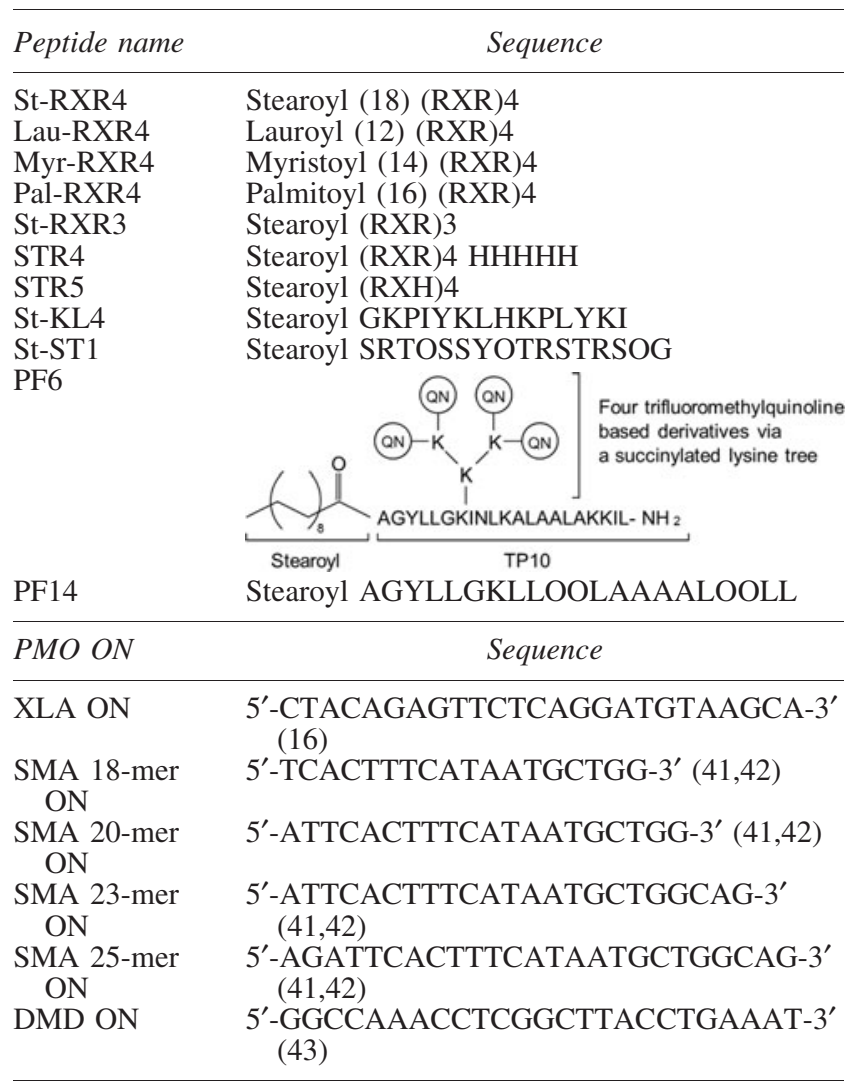

In the peptide, the number between parenthesis denotes the number of carbons in the lipid, while the last number is the number of RXR repeats.

DMD, Duchenne muscular dystrophy; O, ornithine; ON, oligonucleotide; PF, PepFect; PMO, phosphorodiamidate morpholino; SMA, spinal muscular atrophy; X, amino hexanoyl; XLA, X-linked agammaglobulinemia.
KL peptides are based on the theory that amphipathic peptides can readily cross lipid membranes [45]. The KL sequences are designed as secondary amphipathic peptides that might be expected to fold into an alpha helical structure. The ST-series is based on protein sequences with DNA binding properties. Serine and Threonine are abundant in proteins known to interact with ONs [46] and this characteristic might increase the CPPs ability to form stable complexes with the delivered ON.

One of the peptides, RXR4, was chosen as a model peptide to assess the influence of the attached lipid moiety. Lauroyl, myristoyl, and palmitoyl fatty acids were, in addition to stearoyl, conjugated to RXR4 and PMO delivery was assessed using the DMD model system. Further, the most extreme peptides were chosen to assess the toxicity profile of the lipopeptide/PMO treatment.

\section{Peptide synthesis}

Peptides were synthesized by Fmoc solid-phase peptide synthesis using a CEM Liberty microwave peptide synthesizer on an Fmoc-PAL-PEG-PS solid support (Applied Biosystems). Fatty acid-modified peptides were prepared by treatment of the peptide resin with the fatty acid in the presence of 10 equivalents of PyBop and 20 equivalents of diisopropylethylamine in dimethylformamide. The peptide was cleaved from the resin and deprotected using 95\% trifluoroacetic acid (TFA), 2.5\% triisopropylsilane, $2.5 \%$ water for $3 \mathrm{~h}$. The peptides were purified using a Phenomenex Jupiter $10-\mu \mathrm{C} 18$ column $(250 \times 10 \mathrm{~mm})$ : buffer $\mathrm{A}, 0.1 \% \mathrm{TFA}$ in water; buffer B, $0.1 \%$ TFA in acetonitrile. The peptide was analyzed by matrix-assisted laser desorption ionization timeof-flight mass spectrometry using a Voyager DE Pro BioSpectrometry workstation with a matrix of $\alpha$-cyano-4-hydroxycinnamic acid.

\section{Cell culture and transfection}

Plasmid carrying a fusion protein of enhanced green fluorescent protein and luciferase (Clontech) was used to construct a reporter plasmid in which the luciferase cDNA was interrupted by the introduction of a mutated BTK intron 4 containing an A-to-T change known to result in aberrant splicing resulting in the inclusion of the cryptic exon [16]. U2OS cells stably transfected with this construct were cultured at $37^{\circ} \mathrm{C}$ under $5 \% \mathrm{CO}_{2}$ in a humidified incubator. U2OS stable cells were grown in high-glucose Dulbecco's modified Eagle's medium (DMEM) (Invitrogen, Sweden) supplemented with $10 \%$ fetal bovine serum (FBS) (Invitrogen). For PMO ON transfections, cells were plated the day before at a density of 50,000 cells per well in a 24 -well plate.

Murine $\mathrm{H} 2 \mathrm{~K}$ mdx myoblasts [47] were cultured at $33^{\circ} \mathrm{C}$ under a $10 \% \mathrm{CO}_{2}$ atmosphere in high-glucose DMEM with $20 \%$ FBS, $0.5 \%$ chicken embryo extract (PAA Laboratories), and $20 \mathrm{U} / \mathrm{mL}$ interferon- $\gamma$ (Gibco Life Technologies). Twenty thousand myoblasts were seeded in 24-well plates precoated with $200 \mu \mathrm{g} / \mathrm{mL}$ gelatin (Sigma). Twenty-four hours post seeding, cells were differentiated in DMEM supplemented with $5 \%$ horse serum at $37^{\circ} \mathrm{C}$ for $3-4$ days, until fully differentiated into myotubes. Lipopeptides were mixed with $\mathrm{PMO}$ at $10 \times$ final concentration in $40 \mu \mathrm{L} \mathrm{H}_{2} \mathrm{O}$ for $45 \mathrm{~min}$. Lipopeptides/PMO were then diluted in serum-free Opti-MEM (Life Technologies), and each well was treated 
with corresponding amounts of lipopeptide/PMO in a final volume of $0.4 \mathrm{~mL}$. After $4 \mathrm{~h}$, the transfection medium was replaced with DMEM supplemented with 5\% horse serum. Cells were harvested $24 \mathrm{~h}$ post treatment.

SMA type 1 fibroblasts, namely GM03813, were bought from Coriell Cell Repositories. They originate from a 3-yearold male type 1 patient and carry 2 copies of the SMN2 gene. Polymerase chain reaction (PCR) analysis showed that this donor subject is homozygous for the deletion of exons 7 and 8 in the SMN1 gene. Cells were grown in DMEM with $1 \mathrm{~g} / \mathrm{L}$ Dglucose, L-glutamine and pyruvate (Invitrogen) and supplemented with $10 \%$ FBS. Cells were maintained at $37^{\circ} \mathrm{C}, 5 \%$ $\mathrm{CO}_{2}$ in a humidified incubator. One day prior to transfections, cells were seeded at $4 \times 10^{4}$ cells per well in a 24 -well plate. PMO was formulated with each peptide at a molar ratio 5:1 (peptide: $\mathrm{ON}$ ) in water as described above. Transfections were carried out in serum-free conditions and medium with serum was added to the cells after $4 \mathrm{~h}$ of transfection.

\section{$R N A$ extraction and nested reverse transcription-PCR analysis}

Total RNA obtained from $\mathrm{H} 2 \mathrm{~K}$ and $\mathrm{H} 2 \mathrm{~K}$ mdx cells was extracted with Trizol (Invitrogen, UK) and $500 \mathrm{ng}$ of RNA template was used for $12.5 \mu \mathrm{L}$ RT-PCR with a Transcriptor One-Step RT-PCR kit (Roche, Switzerland). The primer sequences for the initial reverse transcription-PCR were: forward, 5'-CAGAATTCTGCCAATTGCTGAG-3' and reverse, 5'-TTCTTCAGCTTGTGTCATCC-3' for amplification of messenger RNA from exons 20 to 26 . The cycle conditions were $95^{\circ} \mathrm{C}$ for $30 \mathrm{~s}, 55^{\circ} \mathrm{C}$ for $1 \mathrm{~min}$ and $72^{\circ} \mathrm{C}$ for 2 min for 25 cycles. The RT-PCR product $(1 \mu \mathrm{L})$ was then used as the template for secondary PCR carried out in $25 \mu \mathrm{L}$ volumes with $0.5 \mathrm{U}$ TaqDNA polymerase (Invitrogen). The primer sequences for the second round for exons 20-24 were: forward (Fwd), 5'-CCCAGTCTACCACCCTATCAGAGC-3' and reverse (Rev), 5'-CAGCCATCCATTTCTGTAAGG-3'. The cycle conditions were $95^{\circ} \mathrm{C}$ for $1 \mathrm{~min}, 57^{\circ} \mathrm{C}$ for $1 \mathrm{~min}$, and $72^{\circ} \mathrm{C}$ for $2 \mathrm{~min}$ for 25 cycles. The products were examined by electrophoresis on a $1.5 \%$ agarose gel. For U2OS stable cells and SMA cells, RNA was isolated from the lysates using the RNeasy kit (QIAGEN). In case of U2OS stable cells, RNA was reverse transcribed into cDNA using the First Strand cDNA Synthesis Kit for RT-PCR (AMV-Roche). PCR was performed with HotStarTaq Plus DNA polymerase (Qiagen). An amount of $100 \mathrm{ng}$ of total RNA was used. Primers for determining splice correction in the U2OS stable cells were as follows: EGFPLuc Fwd-5-CTGGTGCCAACCCTATTCTCCTTC; EGFPLuc Rev-5-CCAGATCCACAACCTTCGCTTCAA-3.

For the SMA cells, RNA was analyzed using the ONESTEP RT-PCR kit (QIAGEN). Primers for the SMN gene have the following sequences: forward, $5^{\prime}$-CCCATATGTCC AGATTCTCTTGAT- $3^{\prime}$ and reverse, $5^{\prime}$ - CTACAACACCCT TCTCACAG- $3^{\prime}$. The program for the RT-PCR was as follows: $55^{\circ} \mathrm{C}$ for $30 \mathrm{~min}$, and then $95^{\circ} \mathrm{C}$ for $15 \mathrm{~min}$ followed by $\left(94^{\circ} \mathrm{C}, 30 \mathrm{~s} ; 54^{\circ} \mathrm{C}, 30 \mathrm{~s} ; 72^{\circ} \mathrm{C}, 30 \mathrm{~s}\right)$ for 26 cycles and finally $72^{\circ} \mathrm{C}, 10 \mathrm{~min}$. The PCR products were analyzed in a $2 \%$ agarose gel in $0.5 \%$ TBE buffer and the bands were visualized by SYBR gold (Invitrogen, Molecular Probes) staining. Gels were documented using the Fluor-S system with a cooled CCD camera (BioRad) and analyzed with the Quantity One software (BioRad).

\section{Nanoparticle tracking analysis}

Particle size was measured using the NTA method. NTA is a recently developed technique which allows the tracking of nanoparticles in liquid suspension on particle-by-particle basis. It measures the Brownian motion of nanoparticles by visualizing and tracking positional changes of each individual particle in two dimensions from which the particle hydrodynamic diameter can be determined [48]. Fresh PMO/ lipopetide nanoparticles were prepared by the same protocol used in transfection experiments. NTA measurements we performed with NS500 nanoparticle analyzer (Nanosight). All measurements were performed at room temperature. Using the script control function, five 30- or 60-second videos for each sample were recorded; incorporating a sample advance and a 5-s delay between each recording. The mean size, mode, and concentration of each sample were measured by the machine.

\section{Toxicity of lipopeptide/PMO delivery}

For the cell viability assay, myotubes in gelatin-coated 96well plates were incubated with lipopeptides for $4 \mathrm{~h}$ followed by further $20 \mathrm{~h}$ incubation in $100 \mu \mathrm{L}$ of DMEM 5\% horse serum. A colorimetric MTS cell viability assay was carried out using $20 \mu \mathrm{L}$ per well of CellTiter 96 Aqueous One solution Cell Proliferation Assay according to the manufacturer's protocol (Promega).

\section{Results}

Efficient splice-switching in SMA fibroblasts and U2OS stable cells following treatment with PepFect/PMO nanoparticles

We have previously demonstrated that in addition to electrostatic interactions, the overall hydrophobicity of CPPs plays also an important role for complex formation $[33,38]$. Given the previous success of the TP10 derived peptides PF6 and PF14 to efficiently convey small interfering RNAs and SSOs into various refractory cells in vitro, we here wanted to evaluate whether such peptides could be exploited also for noncovalent delivery of PMOs. This would open a new avenue for PMO sequence screenings in vitro, since there is a current lack of efficacious systems for PMO delivery. As seen in Figure 1A, both peptides formed a homogenous population of particles with a mean size of around $100 \mathrm{~nm}$. Interestingly, and in contrast to their behavior when used as delivery vehicles for anionic ONs, where particles start aggregating at higher concentrations, the size distribution of complexes does not significantly change by increasing the dose of the formulated ON (Fig. 1A).

We evaluated the efficiency of peptide vehicles from the Pepfect series in delivering PMOs in a recently developed system that represents a model for XLA splicing disorder. Interestingly, PMO formulated with either peptide resulted in a pronounced splice correction activity in U2OS cells stably transfected with a luciferase cDNA interrupted by mutated BTK intron compared with naked PMO. Splice correction was achieved in a dose dependent manner (Fig. 1B).

Next, we validated whether these complexes could promote splice-switching in SMA patient fibroblasts. Using PMOs of two different lengths (20- and 25-mer) formulated with PFs at 1 or $0.5 \mu \mathrm{M}$, nearly complete exon 7 inclusion was observed for 


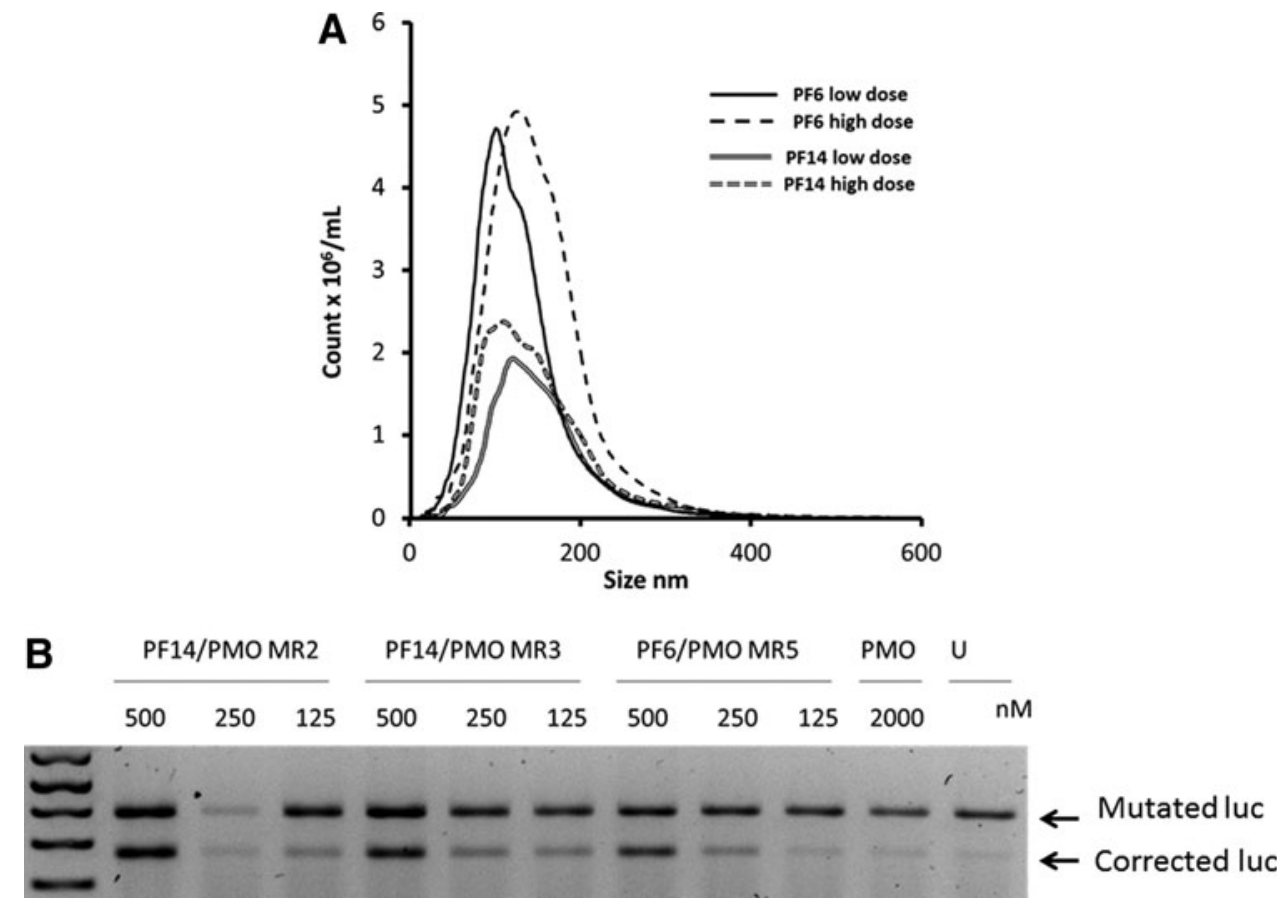

FIG. 1. Nanoparticle tracking analysis (NTA) and splice-correction efficiency of phosphorodiamidate morpholinos (PMOs) formulated by PepFect 6 (PF6) and PF14 shown in U2OS cells stably transfected with a luciferase reporter cloned into a mutated Bruton's tyrosine kinase $(B T K)$ intron as an X-linked agammaglobulinemia (XLA) cell model. (A) NTA of PMO formulated by PF6 and PF14 at two different doses; low dose is the dose used in the cell transfections experiments, while high dose is 10 times more than the low one (1 and $10 \mu \mathrm{M}$ respectively). (B) Splice-correction efficiency by PMOs formulated with PF6 at molar ratio (MR) 5 and PF14 at MR 2 and 3. The upper band represents the aberrantly spliced luciferase (luc) RNA, which includes a pseudoexon sequence, while the lower band is for the corrected form.

the highest concentration using both peptides (Fig. 2A). Even at the lower concentration, the majority of transcript harbored exon 7. The delivery does not appear to be strictly dependent on the length of the PMO used, but longer PMOs were more effective at inducing splice-switching (Fig. 2A). Given the complexity of the PF6 peptide (that in addition to a lipid tail also includes four trifluoromethyl moieties on $\mathrm{Lys}^{7}$ ) and the fact that PF14 appeared equally potent, we next set out to test the PF14 nanoparticles at different doses using PMOs of different length. As seen in Fig. 2B, PF14/PMO induced exon 7 inclusion using 23- and 25-mer PMOs dose dependently and displayed robust activity even at the lowest dose used (175 nM PMO). Similar results were obtained using the shorter PMO sequences (18- and 20-mer), but the activity was slightly lower overall (Fig. 2C). This may be explained by the lower $T_{\mathrm{m}}$ of shorter PMOs, and thus a decreased ability to hybridize to the complementary premRNA. These findings are in line with previous results on PMO-induced splice-switching [49].

\section{Screen of the ability of lipopeptides to deliver splice-switching PMOs in an SMA model}

Given the successful delivery of splice-switching PMOs by PF6 and PF14, the study was extended to see how the peptide sequence could influence the PMO delivery. Selected lipopeptides that represent different classes of CPPs (Table 1) were screened for their ability to deliver a 25-mer PMO that promotes exon 7 inclusion in the SMA cell model. Interestingly, splice-switching activity was markedly increased using all of the tested peptides with marginally the highest effect achieved by the RXR4 peptide conjugated to stearic acid (ST-RXR4) (Fig. 3). RXR4 has previously been used extensively for PMO delivery, although those studies always used RXR4 covalently attached to the PMO [11]. However, none of the selected lipopeptides could improve delivery of splice-switching PMO ONs as much as the PepFect peptides (Figs. 1, 2).

\section{Screen of lipopeptides in mdx myotubes in the DMD model and in healthy myotubes}

When PF14 and the selected lipopeptides were screened in muscle myotubes in the DMD model and in healthy myotubes from mice, some unexpected differences were discovered. The first and most striking difference was that PF14 did not promote exon skipping to the same extent in $\mathrm{H} 2 \mathrm{~K}$ cells (Fig. 4A) as compared with exon inclusion in SMA cells (Fig. 2B, C). Furthermore, PMO formulated with selected members of the newly designed lipopeptides resulted mostly in higher exon 23 skipping activity than that using PF14 in both $\mathrm{H} 2 \mathrm{~K}$ mdx cells and healthy $\mathrm{H} 2 \mathrm{~K}$ muscle cells (Fig. 4B), In the latter case, PMO formulated with the histidine-rich STR5 peptide had the highest efficiency (35\% exon 23 skipping).

The efficiency of the exon-skipping PMO was shown to increase by increasing the dose. Dose-response experiments were performed for PMO formulated with three of the most efficient peptides (St-RXR4, histidine-rich STR4, and DNA-binding StST1) after transfection into H2K mdx cells (Fig. 5A). We also wanted to test the effect of presence of serum on the efficiency of the complexes. The same transfection protocol was performed without the removal of serum. PMO/ lipopeptide nanoparticles 


\section{A PF14-20PMO PF14-25PMO PF6-20PMO PF6-25PMO

A lum 0.5 um lum 0.5 um lum 0.5 um lum $0.5 u m$ control

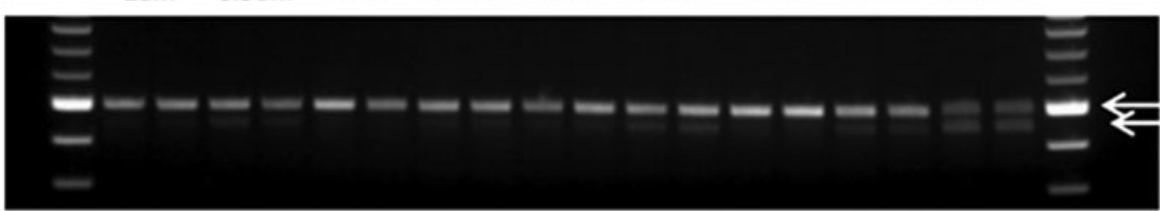

Full length SMN

$\triangle 7$ SMN

B

23-mer PMO

25-mer PMO

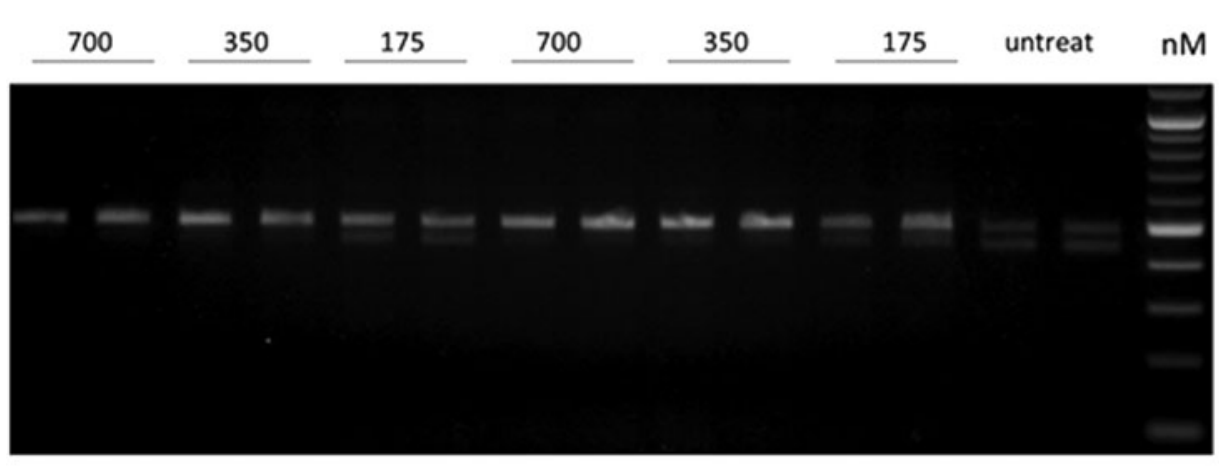

C

18-mer PMO

20-mer PMO

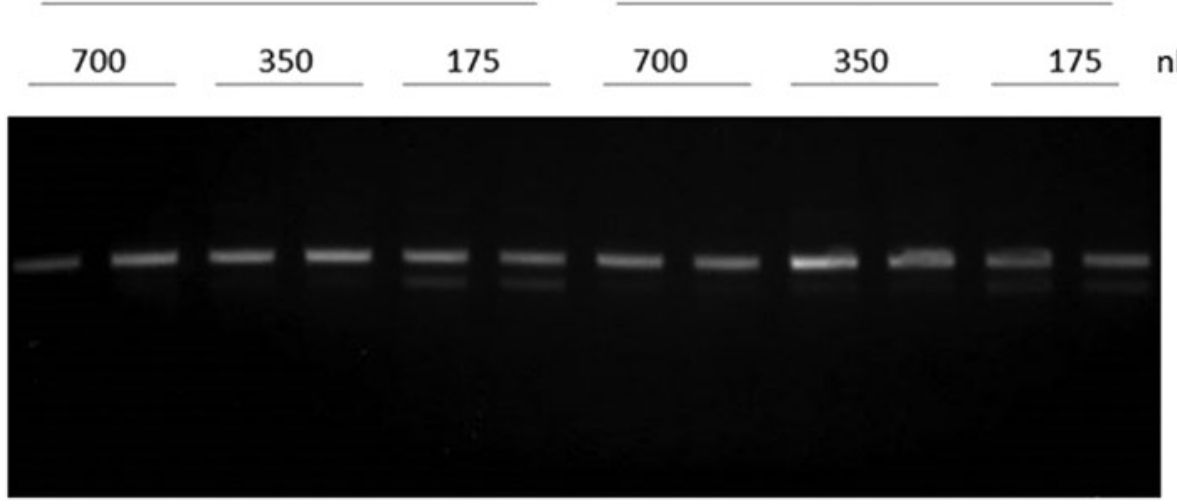
$\mathrm{nM}$

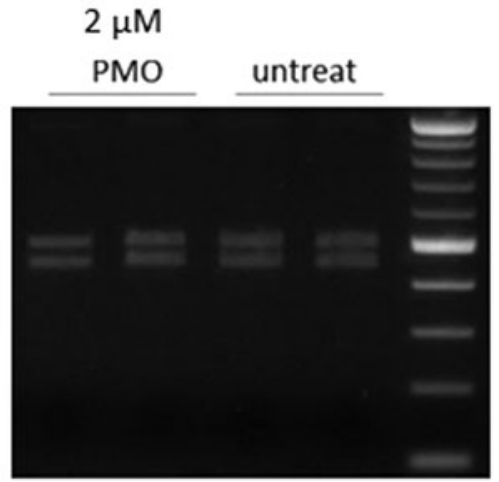

FIG. 2. Exon 7 inclusion efficiency of PMOs formulated with PF6 and PF14 shown in spinal muscular atrophy (SMA) fibroblasts. (A) $0.5 \mu \mathrm{M}$ or $1 \mu \mathrm{M}$ PMO ON of different lengths (20- or 25-mer) delivered by PF14 peptide at ratio 1:5. (B) Dose response of PMOs of different lengths (23- or 25-mer) formulated with PF14. (C) Dose response of PMOs of different lengths (18- or 20-mer) formulated with PF14 and compared with naked PMO. In all SMA gel figures, the upper band represents the full length survival motor neuron gene $S M N$, while the lower band represents delta $7 S M N(\triangle 7 S M N)$.

showed similar levels of exon skipping to those achieved after transfection in serum-free conditions (Fig. 5B).

\section{Lipopeptides form nanoparticles with PMOs}

Particle size is one of the important parameters that influence the efficiency of pharmaceutical formulations. Here, we used the NTA technology to analyze the particle size. All the lipopeptides tested in the study were found to form nanoparticles in combination with PMO. The particle sizes seem to be more dependent on which fatty acid that is used rather than the primary sequence of the peptide. Thus the shorter fatty acid lauric acid (C12) formed a generally smaller mean ( $80 \mathrm{~nm})$ and mode size $(65 \mathrm{~nm})$ compared with stearoylated peptides (C18) (Table 2). Palmitoylated RXR4 (C16) had a smaller mode particle size, but its mean size was more comparable to stearoylated peptides. All lipopeptides promote uptake of PMO SSO, but the length of the attached fatty acid seems to influence the optimal peptide to PMO ratio for efficient delivery.

\section{Screen of lipopeptide/PMO ratios for delivery}

To see if the relative amounts of lipopeptides affect the SSO activity, they were incubated with PMO at ratios between 2 and 7 prior to cell treatments. For most lipopeptides, an increased ratio over PMO was found to improve spliceswitching in the DMD model muscle cells (Fig. 6). The increase seems to be more pronounced in the peptides containing less positively charged amino acids such as the secondary amphipathic peptide St-KL4 (four lysines). In contrast for some peptides such as the more cationic St-RXR3 (six Arginines), the increased peptide ratio over PMO did not improve, but instead decreased, splice-switching activity (Fig. 6). 


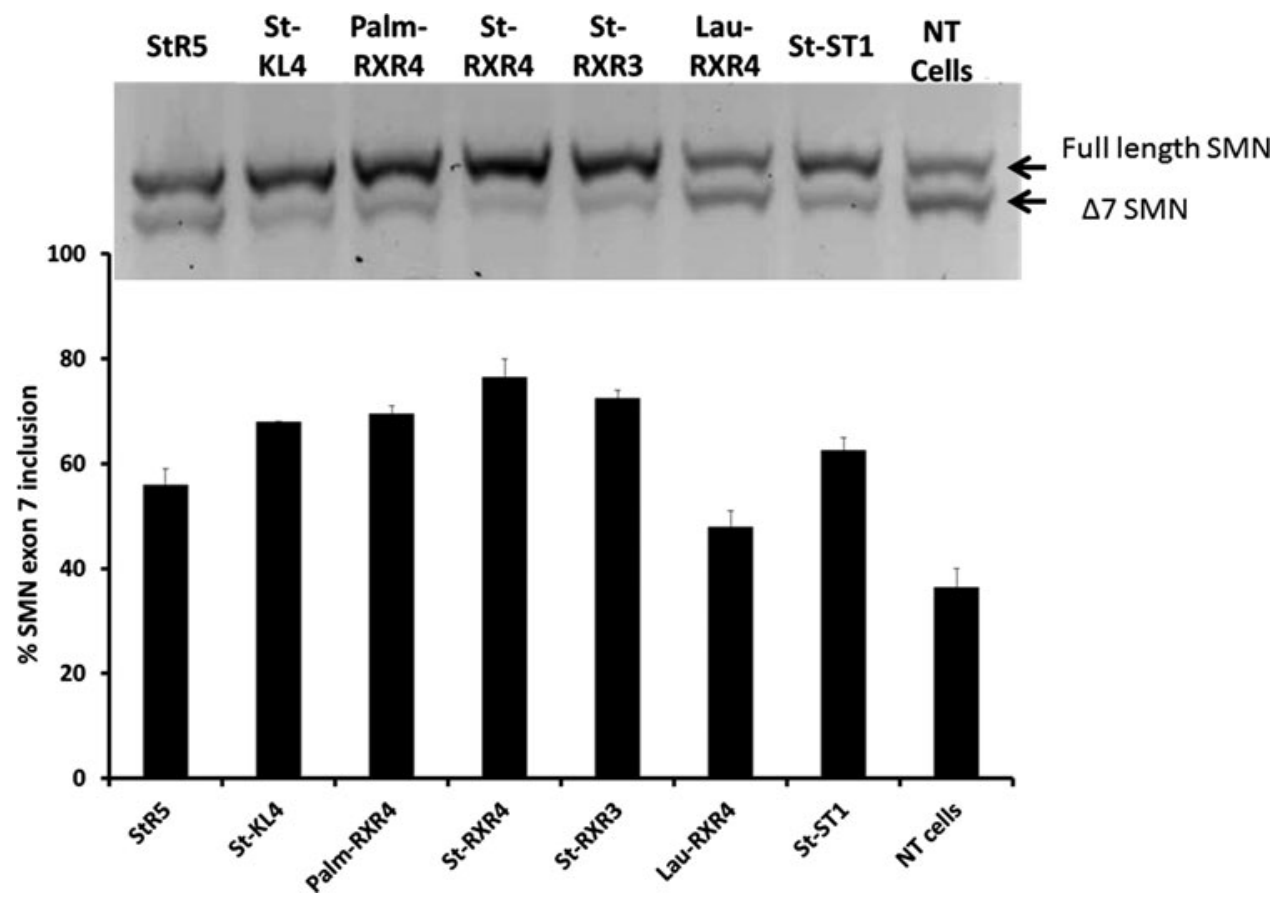

FIG. 3. Exon 7 inclusion efficiency of a 25-mer PMO delivered by selected lipopeptides shown in SMAaffected fibroblasts. PMO was transfected at $1 \mu \mathrm{M}$ concentration after mixing with the selected lipopeptides at molar ratio 1:5. The upper panel represents a $2 \%$ agarose gel picture of the full length $S M N$ versus the $\triangle 7 S M N$. The lower panel shows percentage of $S M N$ exon 7 inclusion calculated as the percentage of the full length band to the sum of the full length and $\Delta 7$ $S M N$ bands. NT, nontreated cells. Results are from at least three experiments performed in duplicate.

A

PMO with
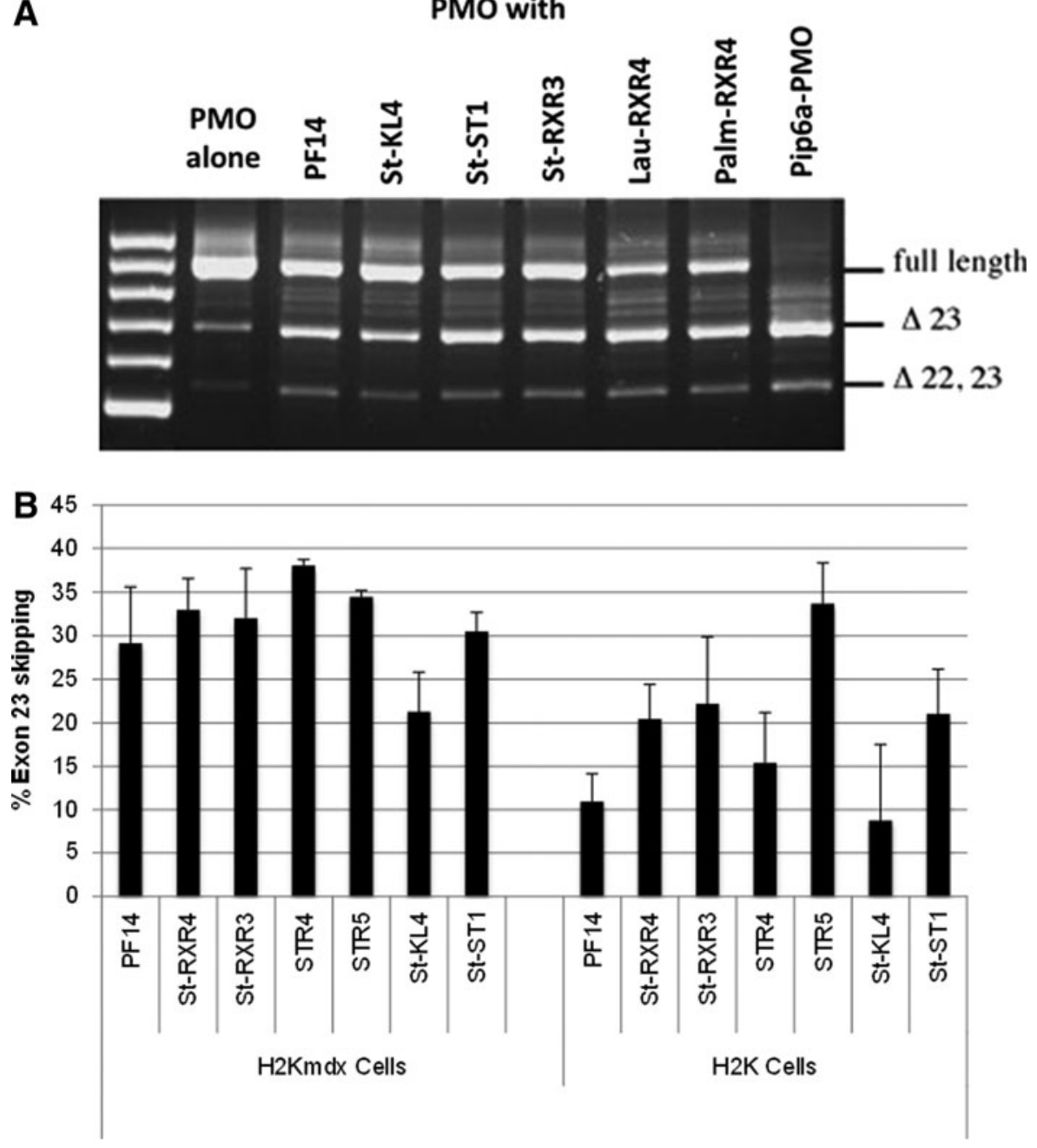

FIG. 4. Exon skipping efficiency of a PMO formulated with selected lipopeptides as shown in $\mathrm{H} 2 \mathrm{~K}$ mdx and in healthy $\mathrm{H} 2 \mathrm{~K}$ myotubes. (A) A 2\% agarose gel showing exon 23 skipping resultant from treatment of $\mathrm{H} 2 \mathrm{~K}$ mdx myotubes with $1 \mu \mathrm{M}$ PMO alone (lane 1), or formulated with lipopeptides at molar ratio 1:5 (lanes 2-7). Control treatment with a PMO covalently conjugated with cell penetrating peptide Pip6a (lane 8); (B) Graph showing percentage of exon 23 skipping, calculated as the percentage of the exon 23 skipped band compared to the sum of the exon 23 and 22 double skipped plus unskipped bands. $\mathrm{H} 2 \mathrm{~K}$ mdx and healthy $\mathrm{H} 2 \mathrm{~K}$ myotubes were transfected with $1 \mu \mathrm{M}$ PMO formulated with the selected lipopeptides at molar ratio 1:5. Graph (B) is not a representation of gel shown in $\mathbf{A}$. Results are from at least three experiments performed in duplicate. 
FIG. 5. (A) Dose response graph showing the exon-skipping efficiency of 25-mer PMOs formulated with St-RXR4, StR4, and St-ST1 lipopeptides in $\mathrm{H} 2 \mathrm{~K}$ mdx myotubes. (B) Exon-skipping of PMO formulated with Pal-RXR4 and with STRR4 and transfected in $\mathrm{H} 2 \mathrm{~K}$ mdx myotubes in the presence or absence of serum. Results are from at least three experiments performed in duplicate.
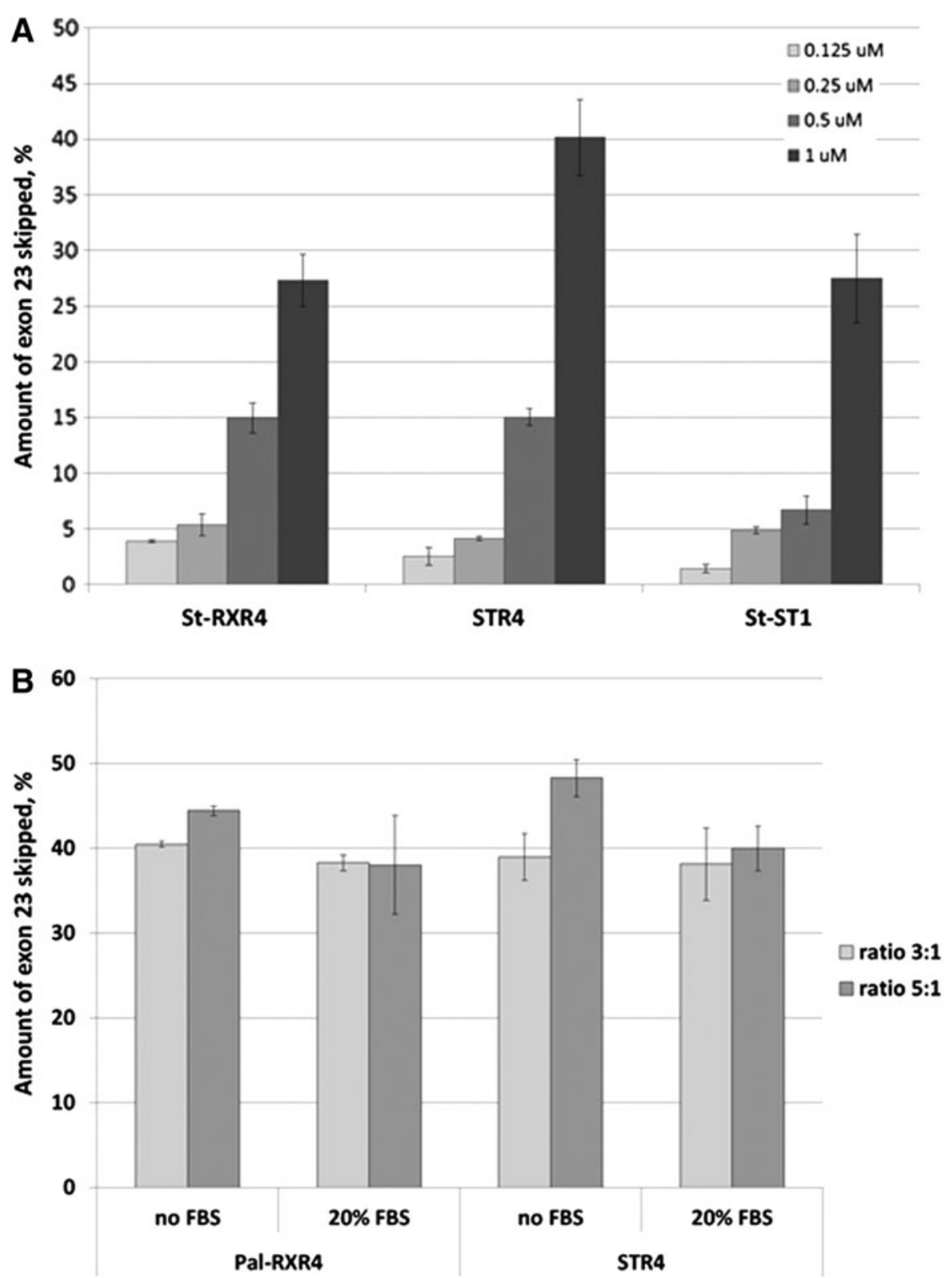

The length of the fatty acid influences delivery efficacy

Table 2. Size Analysis of LipopeptidePMO COMPLEXES

\begin{tabular}{lccc}
\hline & $\begin{array}{c}\text { Mean } \\
\text { particle } \\
\text { Pize }(\mathrm{nm})\end{array}$ & $\begin{array}{c}\text { Mode } \\
\text { particle } \\
\text { size }(\mathrm{nm})\end{array}$ & $\begin{array}{c}\text { Total } \\
\text { concentration } \\
\text { particles/mL) }\end{array}$ \\
\hline St R5 & $133 \pm 5.6$ & $92 \pm 5.1$ & $5.29 \times 10^{8}$ \\
St-KL4 & $148 \pm 2.7$ & $108 \pm 5.3$ & $9.22 \times 10^{8}$ \\
St-KL7 & $120 \pm 3.2$ & $90 \pm 3.3$ & $10.6 \times 10^{8}$ \\
Palm-RxR4 & $119 \pm 3.3$ & $55 \pm 5$ & $5.85 \times 10^{8}$ \\
St-RxR4 & $126 \pm 3.1$ & $82 \pm 2.5$ & $6.08 \times 10^{8}$ \\
St-RxR3 & $125 \pm 4.2$ & $84 \pm 2.9$ & $6.59 \times 10^{8}$ \\
Lau-RxR4 & $80 \pm 1.2$ & $65 \pm 1.9$ & $8.41 \times 10^{8}$ \\
St-ST1 & $136 \pm 4.5$ & $92 \pm 7.1$ & $6.9 \times 10^{8}$ \\
PF14 & $134 \pm 2.8$ & $95 \pm 7.2$ & $4.99 \times 10^{8}$ \\
\hline
\end{tabular}

PMO to lipopeptide ratio $=1: 5$.
To see whether the length of the lipid part of the lipopeptide influences delivery of splice-switching PMO, the most well studied of our CPPs, RXR4, was attached to four fatty acids of various lengths. Stearic acid (C18), palmitic acid (C16), myristic acid (C14), and lauric acid (C12) were each attached to RXR4 as described in the "Material and Methods" section and compared with RXR4 without a fatty acid attachment (Ac-RXR4). The results show that the length of the attached lipid influences delivery somewhat. Attaching a fatty acid of moderate length resulted in an increase in the exon-skipping efficacy of the formulated PMO in $\mathrm{H} 2 \mathrm{~K}$ mdx myotubes (Fig. 7). More than a 4-fold increase in activity was achieved using peptides with $\mathrm{C} 12$ and C14 lipid attachments as compared with the RXR4 peptide alone. However, increasing the lipid length to 16 or 18 carbons resulted in a reduction in activity compared with $\mathrm{C} 12$ and C14. Generally, 


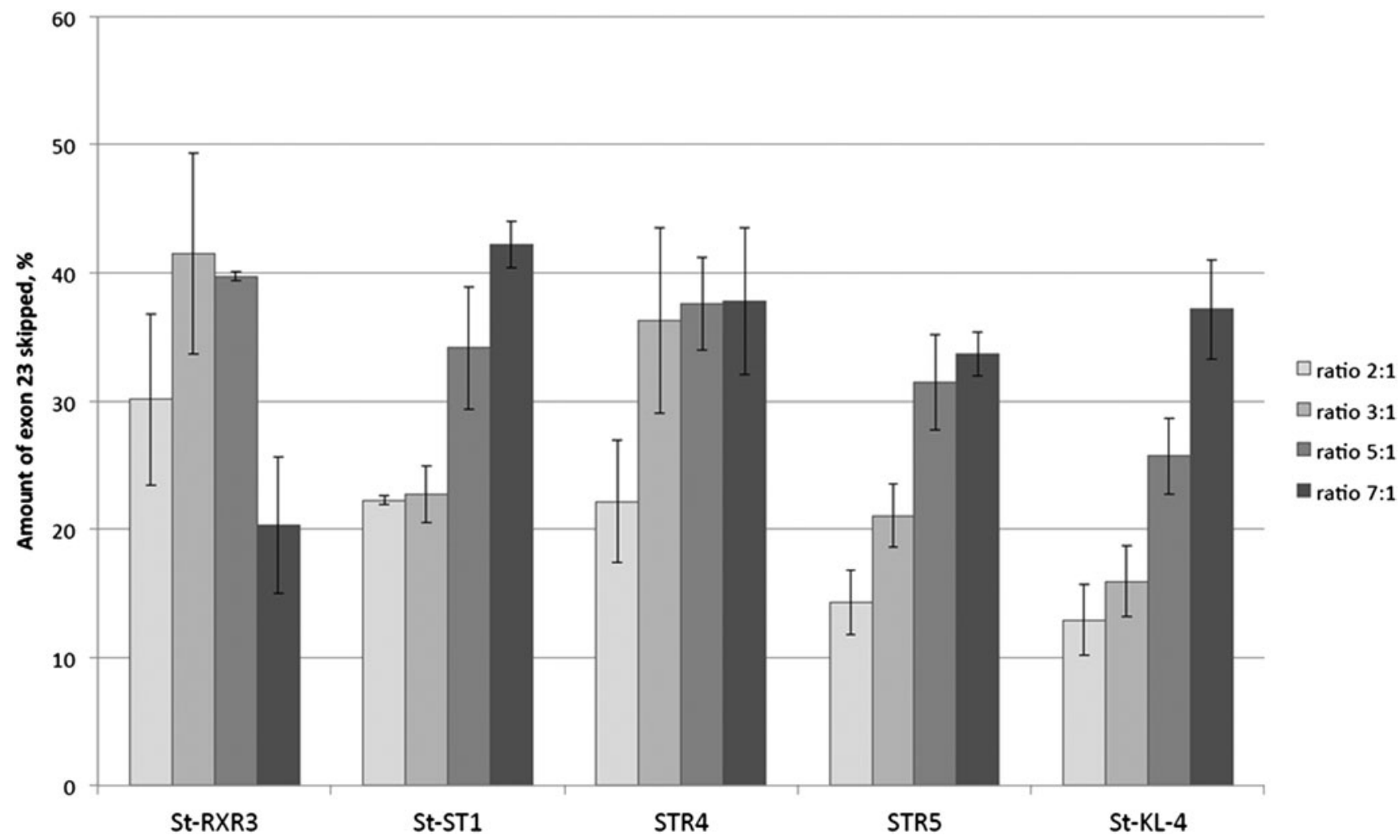

FIG. 6. Exon skipping activity in $\mathrm{H} 2 \mathrm{~K}$ mdx myotubes by $1 \mu \mathrm{M}$ PMO formulated with selected lipopeptides at different molar ratios $(2: 1$ to $7: 1)$. Results are from at least three experiments performed in duplicate.

the difference in efficacy was most pronounced at higher ratios/concentrations.

\section{Toxicity of lipopeptide/PMO delivery}

Several peptides have in previous reports been shown to be more toxic than peptide in combination with cargo [50]. Therefore, a cell viability assay was carried out at a range of concentrations for four selected lipopeptides without the addition of a cargo PMO. The tested lipopeptides showed acceptable cell biocompatibility in the concentration range of 2.5-40 $\mu \mathrm{M}$ except for St-RXR4, which started to show toxicity at $40 \mu \mathrm{M}$ (Fig. 8). No toxicity was detected for any peptide at the working concentration $(5 \mu \mathrm{M})$.

\section{Discussion}

PMO-mediated splice switching is a promising strategy for treatment of several neuromuscular disorders such as Xlinked agammaglobulinemia, spinal muscular atrophy, and

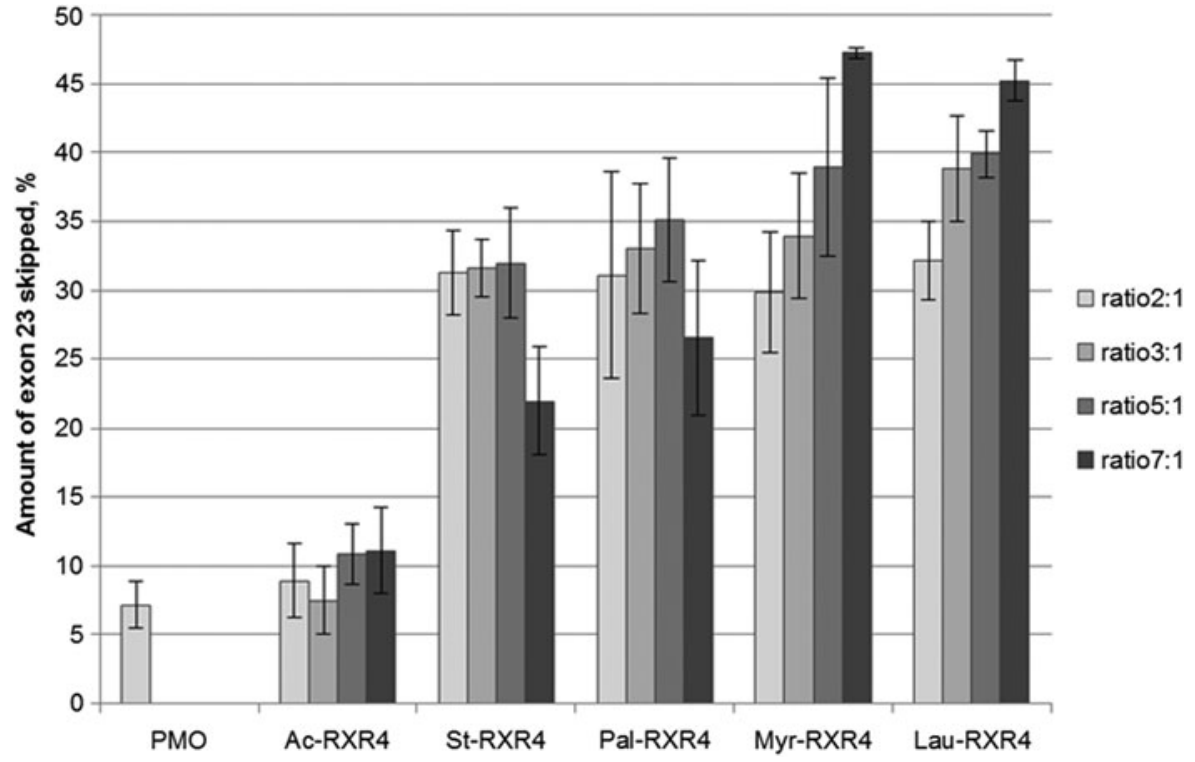

FIG. 7. Exon skipping activity in $\mathrm{H} 2 \mathrm{~K}$ mdx myotubes by $1 \mu \mathrm{M}$ PMO complexed with different lipidconjugated RXR4 at different ratios. Lipid length ranges from $\mathrm{C} 12$ (lauroyl) to C18 (stearoyl). Results are from at least three experiments performed in duplicate. 
FIG. 8. Toxicity of selected lipopeptides measured at concentration range of $2.5-40 \mu \mathrm{M}$. Cell viability was measured by colorimetric 3-(4, 5-dimethylthiazol-2-yl)-5-(3-carboxymethoxyphenyl)-2-(4-sulfophenyl)$2 \mathrm{H}$-tetrazolium cell proliferation assay. No toxicity was detected at working concentration $(5 \mu \mathrm{M})$. Results are from at least three experiments performed in duplicate.

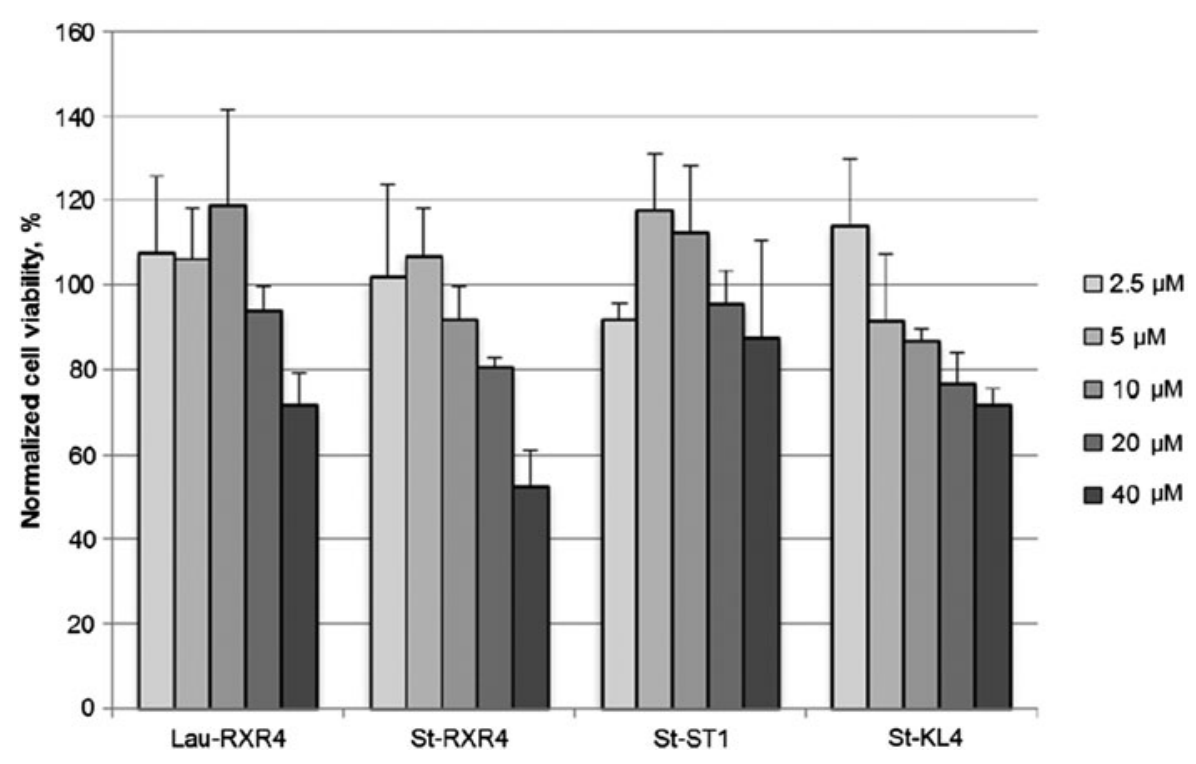

Duchenne muscular dystrophy. However, formulating such charge-neutral ONs has always been a struggle, since most of the commonly used vehicles are designed to complex with anionic ONs. PepFects were among the first lipid-conjugated CPPs reported to promote ON delivery. They have shown efficient delivery of negatively charged ONs in several systems $[37,40]$; however, their ability to form complexes with and deliver charge-neutral PMOs has been unexplored. In XLA-U2OS reporter cells and SMA fibroblasts, we found that both PF6 and PF14 promote enhanced delivery of spliceswitching PMOs of different lengths.

To further improve the formulation and delivery of PMOs, we designed and screened a number of novel lipopeptides of different peptide sequence and with different lipid attachments. Interestingly, many of the lipopeptides showed a marked efficiency in delivery of a 25-mer PMO, exemplified by high levels of exon 7 inclusion in SMA fibroblasts. However, complete exon inclusion in SMA could not be achieved using any of the tested novel lipopeptides and none was better than the previously reported peptide PF14. We further investigated the efficacy of a selected group of the novel lipopeptides in the DMD model $\mathrm{H} 2 \mathrm{~K}$ mdx mouse myotubes. Interestingly, pronounced exon-skipping activity could be achieved by these lipopeptides, which was in most cases even greater than the delivery efficiency of PF14. PMO formulated with histidine-rich STR5 resulted in a highly marked exon-skipping activity in both $\mathrm{H} 2 \mathrm{~K}$ mdx and in healthy $\mathrm{H} 2 \mathrm{~K}$ myotubes. By contrast, lipopeptides with less cationic amino acids such as amphipathic St-KL4 seemed to be less efficient in both $\mathrm{H} 2 \mathrm{~K}$ cell lines compared with SMA fibroblasts. This is expected, since an increase in cationic charge in an attached CPP was shown previously to lead to increased splicing redirection of attached PNA [51,52]. It has been noted before that different CPPs behave differently in different cell lines, and this highlights the importance of choosing the right delivery system for the cell type that is being studied.

In addition, the relative ratio of lipopeptide to PMO seems to affect uptake differently depending on the primary sequence of the peptide. At higher ratios, less cationic peptides such as amphipathic St-KL4 promote a greater activity, while the delivery seems to plateau or even decrease somewhat when using peptides with a higher amount of cationic amino acids (STR4, St-RXR3) (Fig. 6). It can be ruled out that unwanted toxic side effects influence the activities, since none of the peptides included in this study showed any toxicity at the concentrations used (Fig. 8). Depending on the type of peptide used, there might be a threshold value of cationic charges needed to induce endosomal release. At higher concentration, the less cationic peptides might have a greater impact on the endosomal escape and more PMO is released into the cytoplasm/nucleus.

Hydrophobicity is an important factor affecting the efficiency of delivery systems. We wanted to test whether the length of the fatty acid in the lipopeptide can influence delivery efficacy in the two model systems. Four different fatty acids with lengths varying from 12 to 18 carbon atoms were attached to the same well-studied CPP RXR4. The length of the lipid moiety influences both the PMO complex formation and the delivery efficiency. Shorter lipids such as the C12 lauroyl form smaller nanoparticles compared with the longer C18 stearoyl (Table 2). Further, higher lipopeptide to PMO ratios seem to decrease delivery efficiency when using longer chain lipids, while the same ratios improve the uptake when using shorter chain lipids. The reason behind this discrepancy is most likely the increase in hydrophobicity of the larger complexes, which lipid content might prevent the PMO from being released or may interfere with target mRNA binding.

Selected peptides were used to measure the cell viability caused by the lipopeptide/PMO treatments. The longest lipid moiety, stearic acid (C18), attached to the highly cationic RXR4 was used as an extreme to show any toxicity caused by a combination of cationic charges plus a lipid moiety. Amphipathic peptides are known to result in higher cellular toxicities compared with cationic CPPs [53]. So the amphipathic St-KL4 was included in this study, alongside the model peptides StRXR4 and the DNA binding St-ST1. Interestingly, none of the peptides showed any sign of toxicity using a cell proliferation assay at the highest working concentration used $(7 \mu \mathrm{M})$. StRXR4 displayed the most toxicity of the studied lipopeptides with $50 \%$ cell viability at $40 \mu \mathrm{M}$ (Fig. 8). might hamper their cellular uptake. Moreover, the increased 


\section{Conclusions}

Whereas negatively charged ONs have been delivered successfully into many cell types in vitro and into several organs in vivo using cationic polymers as a delivery vehicle, charge-neutral ON analogs such as PNA and PMO were not thought to be compatible with this well-established method. In contrast to PNA ONs, which can be assembled readily in academic laboratories with covalent peptide attachments by total solid phase synthesis or by conjugation techniques, PMOs have only been available commercially and without covalent peptide attachments. Specific conjugation chemistries have been developed for conjugation of PMO to a peptide, but the lack of a convenient cell delivery technique has restricted the use of unmodified PMOs to date. We show here that well-established lipopeptides and novel lipopeptides can form nanoparticles readily with PMOs. Such nanoparticles are efficiently taken up by cultured patient fibroblasts and mouse muscle cells, and the PMO is delivered into the cell nucleus with retained biological activity. The findings presented here prompt further usage of PMO ONs as research tools and suggest future experiments for evaluation of lipopeptide/PMO complexes in animal models of neuromuscular diseases.

\section{Acknowledgments}

This work was supported by the Swedish Medical Research Council (Vetenskapsrådet, VR Unga forskare and EuroNanoMedII). Samir EL Andaloussi is supported by the Swedish Society of Medical Research. Eman Zaghloul is supported by a postdoc grant from Hjärnfonden (The Brain Foundation) at Stockholm, Sweden. Work in the Cambridge laboratory was supported by the Medical Research Council (program no. U105178803).

\section{Author Disclosure Statement}

No competing financial interests exist.

\section{References}

1. Kurreck J. (2003). Antisense technologies. Improvement through novel chemical modifications. Eur J Biochem 270:1628-1644.

2. Bijsterbosch MK, M Manoharan, ET Rump, RLA DeVrueh, $\mathrm{R}$ vanVeghel, KL Tivel, EAL Biessen, CF Bennett, PD Cook and TJC vanBerkel. (1997). In vivo fate of phosphorothioate antisense oligodeoxynucleotides: Predominant uptake by scavenger receptors on endothelial liver cells. Nucleic Acids Res 25:3290-3296.

3. Xu L and T Anchordoquy. (2011). Drug delivery trends in clinical trials and translational medicine: challenges and opportunities in the delivery of nucleic acid-based therapeutics. J Pharm Sci-Us 100:38-52.

4. Järver P and Ü Langel. (2006). Cell-penetrating peptides: a brief introduction. Bba-Biomembranes 1758:260-263.

5. Derossi D, AH Joliot, G Chassaing and A Prochiantz. (1994). The third helix of the Antennapedia homeodomain translocates through biological membranes. J Bioll Chem 269:10444-10450.

6. Madani F, S Lindberg, Ü Langel, S Futaki and A Gräslund. (2011). Mechanisms of cellular uptake of cell-penetrating peptides. J Biophys 2011:414729.
7. Shiraishi T and PE Nielsen. (2011). Peptide nucleic acid (PNA) cell penetrating peptide (CPP) conjugates as carriers for cellular delivery of antisense oligomers. Artif DNA PNA XNA 2:90-99.

8. Abes S, GD Ivanova, R Abes, AA Arzumanov, D Williams, D Owen, B Lebleu and MJ Gait. (2009). Peptide-based delivery of steric-block PNA oligonucleotides. Methods Mol Biol 480:85-99.

9. Shiraishi T and PE Nielsen. (2012). Nanomolar cellular antisense activity of peptide nucleic acid (PNA) cholic acid ("umbrella") and cholesterol conjugates delivered by cationic lipids. Bioconj Chem 23:196-202.

10. Deere J, P Iversen and BL Geller. (2005). Antisense phosphorodiamidate morpholino oligomer length and target position effects on gene-specific inhibition in Escherichia coli. Antimicrob Agents Chemother 49:249255.

11. Abes R, HM Moulton, P Clair, ST Yang, S Abes, K Melikov, P Prevot, DS Youngblood, PL Iversen, et al. (2008). Delivery of steric block morpholino oligomers by (R-X-R)4 peptides: structure-activity studies. Nucleic Acids Res 36:6343-6354.

12. Cirak S, V Arechavala-Gomeza, M Guglieri, L Feng, S Torelli, K Anthony, S Abbs, ME Garralda, J Bourke, et al. (2011). Exon skipping and dystrophin restoration in patients with Duchenne muscular dystrophy after systemic phosphorodiamidate morpholino oligomer treatment: an open-label, phase 2, dose-escalation study. Lancet 378: 595-605.

13. Betts C, AF Saleh, AA Arzumanov, SM Hammond, C Godfrey, T Coursindel, MJ Gait and MJ Wood. (2012). Pip6-PMO, a new generation of peptide-oligonucleotide conjugates with improved cardiac exon skipping activity for DMD treatment. Mol Ther Nucleic Acid, 1:e38.

14. Malerba A, JK Kang, G McClorey, AF Saleh, L Popplewell, MJ Gait, MJA Wood and G Dickson. (2012). Dual myostatin and dystrophin exon skipping by morpholino nucleic acid oligomers conjugated to a cell-penetrating peptide is a promising therapeutic strategy for the treatment of Duchenne muscular dystrophy. Mol Ther Nucleic Acids 1:e62.

15. Havens MA, DM Duelli and ML Hastings. (2013). Targeting RNA splicing for disease therapy. Wiley interdisciplinary reviews. RNA 4:247-266.

16. Bestas B, PM Moreno, KE Blomberg, DK Mohammad, AF Saleh, T Sutlu, JZ Nordin, P Guterstam, MO Gustafsson, et al. (2014). Splice-correcting oligonucleotides restore BTK function in X-linked agammaglobulinemia model. J Clin Invest 124:4067-4081.

17. Seo J, MD Howell, NN Singh and RN Singh. (2013). Spinal muscular atrophy: an update on therapeutic progress. Biochim Biophys Acta 1832:2180-2190.

18. Kole R and BJ Leppert. (2012). Targeting mRNA Splicing as a Potential Treatment for Duchenne Muscular Dystrophy. Discov Med 74:59-69.

19. Berglof A, JJ Turunen, O Gissberg, B Bestas, KEM Blomberg and CIE Smith. (2013). Agammaglobulinemia: causative mutations and their implications for novel therapies. Expert Rev Clin Immunol 9:1205-1221.

20. Tsukada S, DC Saffran, DJ Rawlings, O Parolini, RC Allen, I Klisak, RS Sparkes, H Kubagawa, T Mohandas, et al. (1993). Deficient expression of a B cell cytoplasmic tyrosine kinase in human X-linked agammaglobulinemia. Cell 72:279-290. 
21. Smith CI, B Baskin, P Humire-Greiff, JN Zhou, PG Olsson, HS Maniar, P Kjellen, JD Lambris, B Christensson, et al. (1994). Expression of Bruton's agammaglobulinemia tyrosine gene kinase, BTK, is selectively down-regulated in T lymphocytes and plasma cells. J Immunol 152:557-565.

22. Burglen L, R Spiegel, J Ignatius, JM Cobben, P Landrieu, S Lefebvre, A Munnich and J Melki. (1995). Smn gene deletion in variant of infantile spinal muscular-atrophy. Lancet 346:316-317.

23. Wirth B. (2000). An update of the mutation spectrum of the survival motor neuron gene (SMN1) in autosomal recessive spinal muscular atrophy (SMA). Hum Mutat 15:228-237.

24. Lorson CL, J Strasswimmer, JM Yao, JD Baleja, E Hahnen, B Wirth, T Le, AHM Burghes and EJ Androphy. (1998). SMN oligomerization defect correlates with spinal muscular atrophy severity. Nat Genet 19:63-66.

25. Heier CR and CJ DiDonato. (2009). Translational readthrough by the aminoglycoside geneticin (G418) modulates SMN stability in vitro and improves motor function in SMA mice in vivo. Hum Mol Genet 18:1310-1322.

26. Nurputra DK, PS Lai, NIF Harahap, S Morikawa, T Yamamoto, N Nishimura, Y Kubo, A Takeuchi, T Saito, Y Takeshima, et al. (2013). Spinal muscular atrophy: from gene discovery to clinical trials. Ann Hum Genet 77:435463.

27. Zhou J, X Zheng and H Shen. (2012). Targeting RNAsplicing for SMA treatment. Molecules and cells, 33:223228.

28. Hoffman EP, RH Brown, Jr and LM Kunkel. (1987). Dystrophin: the protein product of the Duchenne muscular dystrophy locus. Cell 51:919-928.

29. Laing NG. (2012). Genetics of neuromuscular disorders. Crit Rev Clin Lab Sci 49:33-48.

30. Aoki Y, T Yokota and MJ Wood. (2013). Development of multiexon skipping antisense oligonucleotide therapy for Duchenne muscular dystrophy. Biomed Res Int 2013: 402369.

31. Futaki S, W Ohashi, T Suzuki, M Niwa, S Tanaka, K Ueda, H Harashima and Y Sugiura. (2001). Stearylated argininerich peptides: a new class of transfection systems. Bioconjug Chem 12:1005-1011.

32. Nakase I, H Akita, K Kogure, A Gräslund, Ü Langel, H Harashima and S Futaki. (2012). Efficient Intracellular Delivery of Nucleic Acid Pharmaceuticals Using CellPenetrating Peptides. Accounts Chem Res 45:1132-1139.

33. Khalil IA, S Futaki, M Niwa, Y Baba, N Kaji, H Kamiya and H Harashima. (2004). Mechanism of improved gene transfer by the N-terminal stearylation of octaarginine: enhanced cellular association by hydrophobic core formation. Gene Ther 11:636-644.

34. Tonges L, P Lingor, R Egle, GPH Dietz, A Fahr and M Bahr. (2006). Stearylated octaarginine and artificial viruslike particles for transfection of siRNA into primary rat neurons. RNA 12:1431-1438.

35. Mae M, S EL Andaloussi, P Lundin, N Oskolkov, HJ Johansson, P Guterstam and Ü Langel. (2009). A stearylated CPP for delivery of splice correcting oligonucleotides using a non-covalent co-incubation strategy. J Control Release 134:221-227.

36. Lehto T, R Abes, N Oskolkov, J Suhorutsenko, DM Copolovici, I Mäger, JR Viola, OE Simonson, K Ezzat, et al. (2010). Delivery of nucleic acids with a stearylated (RxR)(4) peptide using a non-covalent co-incubation strategy. J Control Release 141:42-51.
37. EL Andalouossi S, T Lehto, I Mäger, K Rosenthal-Aizman, II Oprea, OE Simonson, H Sork, K Ezzat, DM Copolovici, et al. (2011). Design of a peptide-based vector, PepFect6, for efficient delivery of siRNA in cell culture and systemically in vivo. Nucleic Acids Res 39:3972-3987.

38. Arukuusk P, L Parnaste, H Margus, NKJ Eriksson, L Vasconcelos, K Padari, M Pooga and Ü Langel. (2013). Differential Endosomal Pathways for Radically Modified Peptide Vectors. Bioconjug Chem 24:1721-1732.

39. de Figueiredo IR, JM Freire, L Flores, AS Veiga and MA Castanho. (2014). Cell-penetrating peptides: A tool for effective delivery in gene-targeted therapies. IUBMB Life doi: 10.1002/iub.1257. [Epub ahead of print].

40. Ezzat K, S EL Andaloussi, EM Zaghloul, T Lehto, S Lindberg, PMD Moreno, JR Viola, T Magdy, R Abdo, et al. (2011). PepFect 14, a novel cell-penetrating peptide for oligonucleotide delivery in solution and as solid formulation. Nucleic Acids Res 39:5284-5298.

41. Singh NK, NN Singh, EJ Androphy and RN Singh. (2006). Splicing of a critical exon of human Survival Motor Neuron is regulated by a unique silencer element located in the last intron. Mol Cell Biol 26:1333-1346.

42. Pao PW, KB Wee, WC Yee and ZA Pramono. (2014). Dual masking of specific negative splicing regulatory elements resulted in maximal exon 7 inclusion of SMN2 gene. Mol Ther 22:854-861.

43. Gebski BL, CJ Mann, S Fletcher and SD Wilton,. (2003). Morpholino antisense oligonucleotide induced dystrophin exon 23 skipping in mdx mouse muscle. Hum Mol Genet 12:1801-1811.

44. Lundberg P, S EL Andaloussi, T Sutlu, H Johansson and Ü Langel. (2007). Delivery of short interfering RNA using endosomolytic cell-penetrating peptides. Faseb J 21:26642671.

45. Mo RH, JL Zaro and WC Shen. (2012). Comparison of cationic and amphipathic cell penetrating peptides for siRNA delivery and efficacy. Mol Pharmaceut 9:299-309.

46. Luscombe NM, RA Laskowski and JM Thornton. (2001). Amino acid-base interactions: a three-dimensional analysis of protein-DNA interactions at an atomic level. Nucleic Acids Res 29:2860-2874.

47. Morgan JE, JR Beauchamp, CN Pagel, M Peckham, P Ataliotis, PS Jat, MD Noble, K Farmer and TA Partridge. (1994). Myogenic cell lines derived from transgenic mice carrying a thermolabile $\mathrm{T}$ antigen: a model system for the derivation of tissue-specific and mutation-specific cell lines. Dev Biol 162:486-498.

48. Filipe V, A Hawe and W Jiskoot. (2010). Critical evaluation of nanoparticle tracking analysis (NTA) by NanoSight for the measurement of nanoparticles and protein aggregates. Pharm Res 27:796-810.

49. Popplewell LJ, C Trollet, G Dickson and IR Graham. (2009). Design of phosphorodiamidate morpholino oligomers (PMOs) for the induction of exon skipping of the human DMD gene. Mol Ther 17:554-561.

50. Maiolo JR, M Ferrer and EA Ottinger. (2005). Effects of cargo molecules on the cellular uptake of arginine-rich cellpenetrating peptides. Biochim Biophys Acta 1712:161172.

51. Saleh AF, A Arzumanov, R Abes, D Owen, B Lebleu and MJ Gait. (2010). Synthesis and splice-redirecting activity of branched, arginine-rich peptide dendrimer conjugates of peptide nucleic acid oligonucleotides. Bioconjug Chem 21:1902-1911. 
52. Deuss PJ, AA Arzumanov, DL Williams and MJ Gait. (2013). Parallel synthesis and splicing redirection activity of cell-penetrating peptide conjugate libraries of a PNA cargo. Org Biomol Chem 11:7621-7630.

53. EL Andaloussi S, P Järver, HJ Johansson and Ü Langel. (2007). Cargo-dependent cytotoxicity and delivery efficacy of cell-penetrating peptides: a comparative study. Biochem J 407:285-292.
Address correspondence to: Samir EL Andaloussi, PhD Department of Physiology, Anatomy, and Genetics University of Oxford South Parks Road Oxford, OX1 3QX United Kingdom

E-mail: samir.el-andaloussi@ki.se

Received for publication September 22, 2014; accepted after revision November 28, 2014. 